\title{
EL MÉTODO DIALÓGICO: UNA EXPERIENCIA INTERDISCIPLINARIA DESDE LA ANTROPOLOGÍA
}

Jonathan Muñoz

(1981-2013)

Resumen: El método dialógico nace con la aplicación interdisciplinaria de los criterios de Mijail Bajtin (2003) y su "lectura en profundidad", método con el cual este filósofo del lenguaje analizaba obras literarias. Esta experiencia se gesta desde la antropología, en conjunto con la historia y la geografía, en una tesis desarrollada en Paso Canoas, comunidad binacional de Costa Rica y Panamá. Palabras clave: Método dialógico, antropología dialógica, Mijail Bajtin, interdisciplinariedad.

Abstract: Dialogic method is born from the interdisciplinary application of the Mijail Bajtin's "reading in depth", method with which this language philosopher analyzed literary works. This experience has sprung from anthropology, in conjunction with history and geography, in a thesis developed in Paso Canoas, binational community of Costa Rica and Panama.

Keywords: Dialogic method, dialogical anthropology, Mijail Baitin, interdisciplinary. 


\section{El método como posibilidad de investigación}

En el mundo de la ciencia, la investigación se vuelve un oficio de perenne reflexión. Discusiones sobre los referentes conceptuales, el método, las técnicas, cronogramas y demás interpelan a múltiples criterios en la formulación de un diseño. El planteamiento del problema, objetivos, justificación, la delimitación del tema y demás procesos indican posibles caminos para efectuar la investigación, según las perspectivas occidentales de lo que se denomina quehacer científico.

Se argumentará, en primera instancia, sobre lo que significa un método en el plano de la investigación antropológica y las posibilidades y alcances de este. Luego, se hará una síntesis de la teoría dialógica de Mijail Bajtin (2003), para comprender cómo esta propuesta permite construir un método, a partir de una experiencia de tesis desarrollada en la comunidad fronteriza de Paso Canoas, entre Costa Rica y Panamá. Finalmente, se expondrán elementos acerca de la pertinencia del método dialógico implementado en la investigación

Cual figura de alegoría, emerge del mar de los recuerdos una manera muy peculiar de comprender lo que es un método, a partir de una metáfora plasmada tras varias experiencias vividas en los años de estudiante, cuando el profesor Rolando Quesada hablaba de metodología. Se planteaba como cuestionamiento inicial lo siguiente: estando en la ciudad de San José y queriendo ir a la ciudad de Puntarenas, ¿cómo se hace para llegar? Para ello, se debe primero plantear el método; es decir, la ruta por la cual se desplazará.

Existen varias posibilidades: como primera, puede tomar la Ruta Interamericana 1, con las autopistas General Cañas y Bernardo Soto, así como la Cuesta de Cambronero. Otra opción sería viajando a San Carlos de Alajuela, de ahí a Upala, comunidad fronteriza con Nicaragua, tomar luego la ruta hasta La Cruz de Guanacaste para alcanzar la ruta Interamericana 1 y después al sureste, hasta el puerto de Puntarenas. Si se quisiera complicar, puede ir rumbo a Paso Canoas, límite con Panamá. De ahí se parte a Ciudad Panamá, se cruza el Canal de Panamá en bote hasta la ciudad de Colón. Seguidamente, en una avioneta, se llega a Changuinola, en Bocas del Toro, costa atlántica panameña, para tomar un bus que venga a San José. Bajándose en Santo Domingo de Heredia, se puede tomar la radial hacia Escazú por La Uruca, para 
conectar con la autopista Próspero Fernández, llegando a Puntarenas a través de la ruta 27. Y así, infinidad de posibilidades...

Según se planteen los objetivos, quien investigue decidirá cuál ruta (método) le sirve más. Si se busca llegar a la meta ágilmente sin obstáculos, la primera ruta (considerada como la más lógica) será la óptima. Si se necesita ampliar el panorama de conocimiento, tomando rutas que parecen desviadas, pero al final llegan al destino, las rutas 2 y 3 parecen las indicadas. Eso sí, que la desviación responda a una necesidad efectiva. Es así que se plantea que para llegar a la ciudad de Puntarenas desde la ciudad de San José hay múltiples rutas; de igual modo, para investigar hay diversidad de métodos. "Un método, sea cual fuere, consiste en algún procedimiento, que puede ser descrito en un manual y eventualmente llevado a la práctica; indica que se deben seguir ciertos pasos para arribar a determinado resultado" (Haba, 1994, p. 111).

Una vez escogido el método, se plantean las técnicas; es decir, la manera en que se logrará el acometido tras definir la ruta (con respecto a la metáfora que se plantea). Bajo esta perspectiva, la técnica correspondería al vehículo para llegar a la ciudad de Puntarenas; es decir, en motocicleta, avioneta, automóvil, caminando, en bus y demás, o inclusive pueden surgir combinaciones estratégicas; por ejemplo, desplazarse en bus de San José a San Ramón, donde un amigo le recogerá en su carro, le deja en Barranca y de ahí toma taxi para terminar el viaje. Las necesidades de los objetivos igualmente indicarán la viabilidad de las técnicas.

Finalmente, se planea la estrategia metodológica, todos los elementos de logística y de implementación del método y las técnicas en una estructura organizada, con su debida reflexión de fondo en cuanto a pertinencia. Siguiendo con la idea de viajar al puerto de Puntarenas, se decidió viajar en bus por la ruta Interamericana. Para ello, previamente hay que comprar pastillas para el mareo, comida para el camino, alistar equipaje y reservar los tiquetes en la terminal de buses. Durante el viaje, se deberá ser simpático con el chofer y quienes acompañan, cantar canciones de viaje, dormir un rato, comer y tomar fotografías. Llegando a Puntarenas, se compartirá con el pueblo la experiencia y se mostrárán fotos, para luego deleitarse con un "churchil" y comer un vigorón mientras se observa el atardecer en el muelle. 
Cuando se desarrolla una investigación, se necesita un trabajo previo de preparación y contextualización del tema, para conocer dónde y con quién se trabajará. Luego, se plasma el orden de implementación de las técnicas, según el método escogido, en las distintas etapas y fases del trabajo, para concluir con la retroalimentación de la investigación. No obstante, presentar una noción esquemática de lo que se hará no implica una receta como tal. Se pueden replantear criterios, innovar, tomar elementos de otros métodos y articular nuevos métodos, en un claro ejercicio de interseccionalidad metódica coherente. "La metodología puede, ciertamente, llegar a influir sobre el uso de métodos o incidir en la elección de ellos, o motivar la introducción de cambios en sus 'recetas' o impulsar la creación de otras nuevas” (Haba, 1994, p. 111).

Habiendo compartido tan simpática metáfora, se plantea que la necesidad de desarrollar el método dialógico, como posible ruta entre muchas existentes, respondió a las necesidades particulares de una investigación de tesis llevada a cabo en Paso Canoas entre 2009 y 2011, bajo el título "Construyendo identidades en armonía con los vecinos. Un estudio antropológico de la comunidad binacional de Paso Canoas, frontera Costa Rica-Panamá. Una aproximación dialógica”. Este proyecto buscaba explicar los procesos y dinámicas sobre las cuales se construía la identidad nacional en las personas "pasocanoenses", en tanto forman una mezcla de costarricenses y panameños conviviendo.

Paso Canoas es una comunidad binacional, tiene una parte en Costa Rica y una en Panamá, lo cual genera una discusión interesante. La identidad nacional, como punto de partida y de interés de la investigación, se construye en dinámicas de diferenciación y exclusión del otro. Se parte de que las nociones de frontera y límite nacen de la identidad nacional, en cuanto responden a dividir territorios marcados por un discurso estatal-nacional por diferenciación (soy costarricense porque no soy panameño o inclusive nicaragüense o colombiano, por ejemplo).

Es obvio que una persona puede identificarse más allá de un país (un costarricense o panameño puede hacerlo como latinoamericano, por ejemplo), pero el discurso nacional es el que interesó para esta investigación. Se partió de reflexionar de que: 
...la frontera entre dos Estados es una delimitación simétrica de competencias similares; en el límite fronterizo expiran esas competencias. La formación del Estado territorial es, además, un acto de consolidación de la soberanía interna y la expresión de diversas facultades de gobierno, administración y afianzamiento de la identidad nacional (Morales y Romero, 2000, p.26-27).

Sin embargo, esto no pasa como tal en Paso Canoas. Aquí los sujetos costarricenses y panameños promulgan sus distinciones nacionales e incorporan al otro del que se cimentan, al adscribirlo como elemento fundamental del yo. Por ejemplo, doña Elisa, una señora costarricense casada con un señor panameño, cuenta lo siguiente:

Vea muchacho, la convivencia al principio ha sido muy difícil entre nosotros, porque hemos tenido que aprender comidas, dichos, gustos y demás del otro. Hemos peleado mucho, pero todo se arregla cediendo en algunas cosas. Para nosotros como esposos, nos importa el amor que nos tenemos, que queremos estar juntos. Igual pasa aquí en Paso Canoas: lo costarricense y lo panameño aquí se conocieron, se enamoraron, se casaron y ahora viven juntos, porque ambos se complementan en todo sentido. ¿Qué le parece? (Doña Elisa, comunicación personal en Paso Canoas, 27 de marzo de 2010).

Parece contradictorio, pero, según la teoría dialógica de Mijail Bajtin, es posible, cuando señala que "[...] la obra de Dostoievski se ha fragmentado en un conjunto de construcciones filosóficas independientes y mutuamente contradictorias, defendidas por sus héroes" (Bajtin, 2003, p.13). Por eso, se exploró esta teoría, la cual arrojó la posibilidad metodológica de estudiar estas contradicciones coexistentes en las personas adultas de Paso Canoas con una armazón teórica sólida.

Durante esta investigación, se tuvo que identificar los diferentes trámites migratorios para salir de Costa Rica e ingresar a Panamá (y viceversa); así como recorrer Paso Canoas, tanto de su lado panameño como costarricense, para reconocer en qué puntos se dibuja el límite y la división de ambos lados 
de la comunidad. Fue necesario identificar festividades y lugares principales de cada uno de estos lados de la comunidad (así como sitios de hospedaje, comida y comercio), manejar horarios de buses entre las ciudades de San José, Paso Canoas y Panamá, de Ciudad Neily y David (como cabeceras políticas de Paso Canoas costarricense y panameño), entre otras cosas. Y, por supuesto, hubo elementos que fueron surgiendo en el transcurso de la investigación, los cuales demandaron un replanteamiento de ciertos lineamientos sobre ésta.

\section{Teoría dialógica: el aporte de Bajtin}

La propuesta metodológica empleada en la tesis nació de los planteamientos teóricos del filósofo ruso del lenguaje Mijail Bajtin, quien brinda un panorama que revolucionaría el mundo intelectual a inicios del siglo XX. En el ámbito artístico predominaba el Formalismo, corriente que valoraba las obras por su forma, tratando de encontrar universalismos desde la técnica. En las obras escritas, se hablaba así de la literaliedad de la obra desde su estructura (Medvedev y Bajtin, 1994; Voloshinov y Bajtin, 1995). Ante esto, Bajtin propone que el valor de la obra se percibe en cuanto es elaborada para que un público le replique.

Con esto, él habla de un diálogo entre el autor y el espectador, en el entendido de que el artista produce su pieza en tanto conseguirá una respuesta de aceptación por parte de quienes la contemplan. Es así que el autor se vuelve sujeto de sus espectadores: él es cuando los otros lo definen. El "yo", concebido como la estructura de organización de la conciencia a partir de percepciones propias, se vuelve bivocal, pues el "otro" habita en él, habla a través de su conciencia y lo edifica como individuo, en conjunto con sus percepciones individuales (Alejos, 1998; Bajtin, 2003). Es así que el individuo como un "yo", en presencia del "otro", se vuelve sujeto a este. De tal modo que, el "otro" que no es "yo" se constituye parte del "yo". En este juego de contradicciones coexistentes que dialogan, Bajtin plantea que se construye así una percepción del mundo opuesta a la dialéctica, la cual denominó dialógica. 
Desarrolló su teoría a través de la obra de un escritor ruso que no era congraciado por sus colegas, Fiódor Dostoievski, puesto que sus personajes parecían tener vida propia más allá de la obra, cual si fueran seres vivientes reales con conciencia propia. En sus obras, hablan muchas voces de los personajes, autónomos de su autor. Esta característica corresponde a una novela dialógica o polifónica, donde "Dostoievski puede parecer caótico y la estructura de sus novelas un conglomerado de materiales heterogéneos y de principios incompatibles" (Bajtin, 2003, p. 17). Algunos conceptos de la teoría dialógica se expondrán a continuación.

Primero está la vivencia, reconocida como el proceso social de interiorización de las experiencias de la cotidianeidad con el "otro", las cuales son asimiladas en la conciencia (Bubnova, 1996). Con esto, se puede ver la posibilidad de que el panameño incorpore dentro de sí distintas vivencias sobre celebraciones o prácticas culturales del costarricense y viceversa. Luego se presenta la valoración, correspondiente a la dotación de sentido de una vivencia por parte del individuo. Este proceso produce una resignificación de la experiencia vivida (Medvedev y Bajtin, 1994). Un costarricense puede valorar ventajoso conocer las particularidades de su vecino panameño para cimentar una convivencia binacional estable. Igual procedería una persona panameña.

Otro concepto importante es el de excedente de visión. Es la porción del "yo" que el "otro" posee del sujeto, puesto que la identidad depende de la relación con el "otro". Ésta se construye a una potencia infinitesimal, es inconclusa. Siempre habrá "otros" por conocer y que participarán en la construcción del "yo" (Alejos, 2006). Los costarricenses que habitan la zona fronteriza reconocieron eso en virtud de saber qué parte de su identidad se construye en convivencia con el vecino internacional; en este caso, el panameño. Este paso se lleva a cabo en un ejercicio de extra posición, con la capacidad de cambiar de umbral ante distintas circunstancias, "de abandonar momentáneamente su propio eje axiológico y trasladarse al lugar del otro [...]" (Alejos, 2006, p. 52).

Este concepto resultó importante para comprender cómo las personas costarricenses se abrían al discurso panameño y viceversa. Como cuenta Fanny, una joven costarricense casada con un joven panameño: 
Mi esposo me cuenta cómo desde la escuela y el colegio les enseñan a amar la patria. Que para ellos, Panamá ha sido humillada por otros países, sin conocer la grandeza de la nación. Costa Rica les quitó Coto, Estados Unidos los explotó con el canal y Colombia siempre los trató mal. No obstante, Costa Rica siempre ha apoyado a Panamá en todo momento y eso hace la diferencia (Fanny, comunicación personal en Paso canoas, 28 de febrero de 2010).

El concepto con el cual se abordó la naturaleza de combinación estratégica de identidades nacionales fue el de cronotopo. Aquí, se habla de la cualidad de la palabra de tener sentido y valor en un eje de espacio-tiempo particular (Bajtin, 2003). La noción de "identidad panameña" e "identidad costarricense" que se maneja hoy en Paso Canoas nace desde los cronotopos con los cuales los costarricenses y panameños se encontraron en el siglo XIX, cuando se empezó a delimitar el territorio de las dos naciones: un panameño chiricano que empieza a poblar la Zona Sur de Costa Rica por estar deshabitada, versus un costarricense del Valle Central que atiende el llamado del Gobierno a repoblar la región, tras el avance invasor de los vecinos.

En este sentido, Laura, una joven descendiente de panameños que colonizaron el Sur de Costa Rica, afirma que:

Mi papá me cuenta que cuando llegó gente del Valle Central, las cosas empezaron a cambiar. Nos hicimos ticos con ellos aquí. Cuando nació Buenos Aires, aquí se le llamaba el "distrito chiricano", pero ya no [...] Cuando un descendiente de chiricano muere, se le despide con acordeón y saloma, y para la gente se vuelve todo un espectáculo. No hay conciencia de la identidad (Laura, comunicación personal en Potrero Grande de Buenos Aires, 27 de noviembre de 2009).

Para llevar a cabo este abordaje, se retomó además el concepto de cultura que brinda la teoría dialógica: espacio ideológico que ancla una colectividad en la conciencia de su propia identidad. La cultura se manifiesta en la ideología a través de sus prácticas concretas: lenguaje, instituciones y reproducción social al asimilarse e interiorizarse en el sujeto (Cros, 1997). Es 
así que, esa identidad reconocida como propia vive en diálogo con otras cercanas, puesto que no son aisladas. Se habla así de un proceso de interrelación del "yo" con el "otro". Puede ser externo al enunciar o interno al asimilar la vivencia con el "otro" y valorarla (Voloshinov y Bajtin, 1992).

El diálogo se traduce en un evento de comunicación donde un "yo" habla a un "tú" sobre un "él", en un medio colectivo, desde conciencias individuales y en un código socialmente aceptado como condición sine qua non del diálogo. Es decir, se reconoce la diferencia entre un "yo" y un "tú". No podemos hablar de diálogo bajtiniano cuando interpelamos a mismidades. Por lo tanto, el proceso de diálogo se denota en Paso Canoas mediante la vivencia intersubjetiva de los discursos nacionales de Costa Rica y Panamá conviviendo en un mismo espacio. Que ambos se entremezclan y crean una posibilidad de identidad "pasocanoense" es cierto, pero eso no implica que la particularidad de ser costarricense o panameño desaparezca.

Un ejemplo estratégico de cómo se integran los discursos queda demostrado con la crisis bananera de 1980, donde tanto costarricenses como panameños enfrentaron una crisis de desempleo sin precedentes, donde Paso Canoas fungió como paliativo:

Viera qué terrible ver el abandono en que quedamos. La bananera nos había dado casa a los empleados y teníamos nuestro sueldo. No éramos ricos, pero vivíamos muy bien. Cuando las bananeras se van, nos dicen que no tienen para liquidarnos y que nos van a echar de las casas. No sabíamos qué hacer. El Gobierno nos ayudó con fondos para cooperativas, pero casi todas han quebrado. Estamos cada vez más pobres. Al menos con la frontera cerca [refiriéndose a la comunidad de Paso Canoas], encontramos todo a buen precio para que nos rinda (Francisco, comunicación personal en Malagueto de Barú, Chiriquí, Panamá, 26 de diciembre de 2009).

Los procesos de identidad, a partir de la relación del sujeto con los otros, se cimentan "en una triada básica de relaciones que son: yo-para-mí, otro-paramí y yo-para-otro" (Alejos, 2006, p. 53). Yo-para-mí que funge como la interpretación subjetiva que tengo de mí mismo, yo-para-otro como la identidad 
que busco promulgar al "otro" buscando una respuesta de aprobación y otropara-mí referido a las interpretaciones subjetivas que tengo del "otro" y que me permiten interactuar con él.

Estas lógicas calzan dentro de los esquemas de la comunicación, donde un emisor expresa un mensaje a un receptor sobre un tema particular, en un código socialmente aceptado o canal. En este sentido, Bajtin en su teoría estipula que el autor de una obra crea un texto literario para que un lector lo reciba e interiorice. Dicho texto se referirá a un héroe, su vida y sus hechos, a partir de presentar esa anécdota en un discurso socialmente aceptado y asimilable. Este proceso se sintetiza en el siguiente diagrama.

Figura 1

Proceso de diálogo según Bajtin (tomado de: Muñoz, 2011)

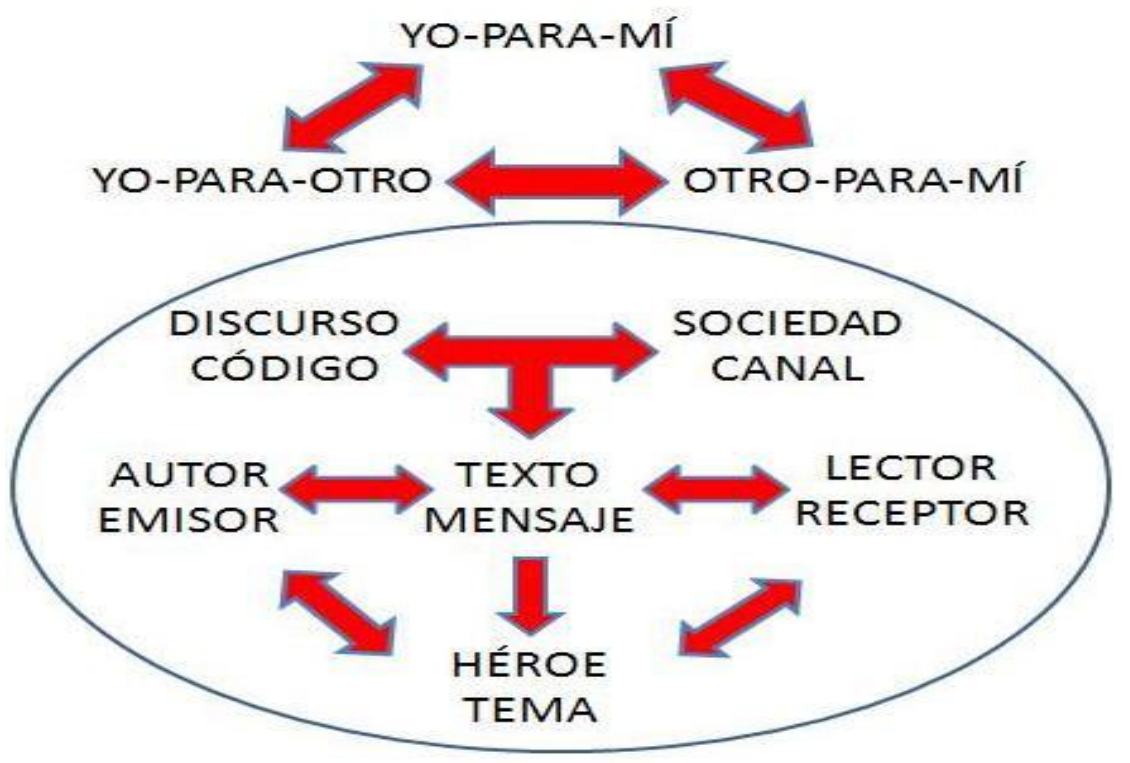

De este modo, indicando que lo dialógico gira en torno a lo social, a la vida cotidiana, se puede hacer investigación dialógica con la antropología (o cualquier otra ciencia social). En este caso, presenta al habitante de Paso Canoas como el "héroe" sobre el cual se escribe. Bajtin indica que es posible concebir la vida cotidiana como una novela dialógica que constantemente se escribe, donde mi "yo" es el héroe en un espacio novelesco, cuando afirma que a Dostoievski le interesa el héroe "[...] en tanto que es un punto de vista particular sobre el mundo y sobre sí mismo, como una posición plena de 
sentido que valore la actitud del hombre hacia sí mismo y la realidad circundante" (Bajtin, 2003, p. 73). Este espacio novelesco es un conjunto de relaciones en el tiempo entre lugares, medio, elementos y las personas que este presupone. Lo social se articula en una urdimbre de significaciones: lo social es una tela, cuyos hilos se entrelazan en distintos planos, cuyo bastidor es la ideología.

Esta metáfora se comprende mejor con el planteamiento de la conciencia social hacia el medio, el suelo y la tierra. El medio refiere como condicionante externo; el suelo es el sistema orgánico que desarrolló su espíritu; y la tierra se refiere al vínculo con las cosas. En otras palabras, lo resume en espacio, tiempo y marco de relaciones con objetos y otros sujetos. Estos lineamientos Bajtin los utilizaba al hacer la lectura en profundidad de los textos literarios. Asumiendo que la lectura tenía voces ocultas, que no salían a la luz tras una lectura superficial, se hacía necesario explorar los elementos que particularizaban las dimensiones de lugar, momento, materialidad y vínculos sociales desde estas voces para explicar por qué existían.

Asimismo, Bajtin (2003), desde sus estudios de la obra de Dostoievski, planteó una tipología discursiva con la cual daba lineamientos para encontrar diálogos y voces en un texto. Habla de tres tipos de discurso según la figura anterior. El primero va orientado al objeto y se remite al habla cotidiana. El segundo, a la representación y responde a dos fenómenos: la individualidad, en donde, la expresión y la tipificación, sobre el cual se identifica una población, en tanto le imprime una identidad nacional o regional, un territorio y una tradición lingüística histórica. Los costarricenses saludan diciendo "pura vida" o los chiricanos muestran impresión con la interjección "meto". Entiéndase que estas expresiones no responden a todas las personas bajo esa identidad, pero sí a la mayoría.

Finalmente, Bajtin expone los tipos de discurso de orientación bivocal, en los cuales se encuentra diálogo. Puede ser de una sola orientación, abocada a la estilización (copia de estilo de alguien más), icherzählung (narración en primera persona), relatos de otros desde el narrador o por un discurso de títere, donde alguien expone sus criterios a través de otro. Puede ser de orientación múltiple, a través de la parodia (técnica que invierte el sentido del discurso), un cambio de acentuación, en cambio de planos 
(personajes parodiándose entre sí, personajes parodiando al narrador y viceversa) o en la narración de primera persona. O puede ser de tipo activo, el cual se aboca a lo oculto, a través de una confesión polémica, de una réplica de diálogo, de discurso ajeno colado en el propio, de una autobiografía o de un diálogo oculto. En este último, las palabras del "otro" no se oyen, pero emergen desde el discurso del "yo" (Bajtin, 2003). Esto se resume en el siguiente diagrama.

Figura 2

Tipología discursiva bajtiniana

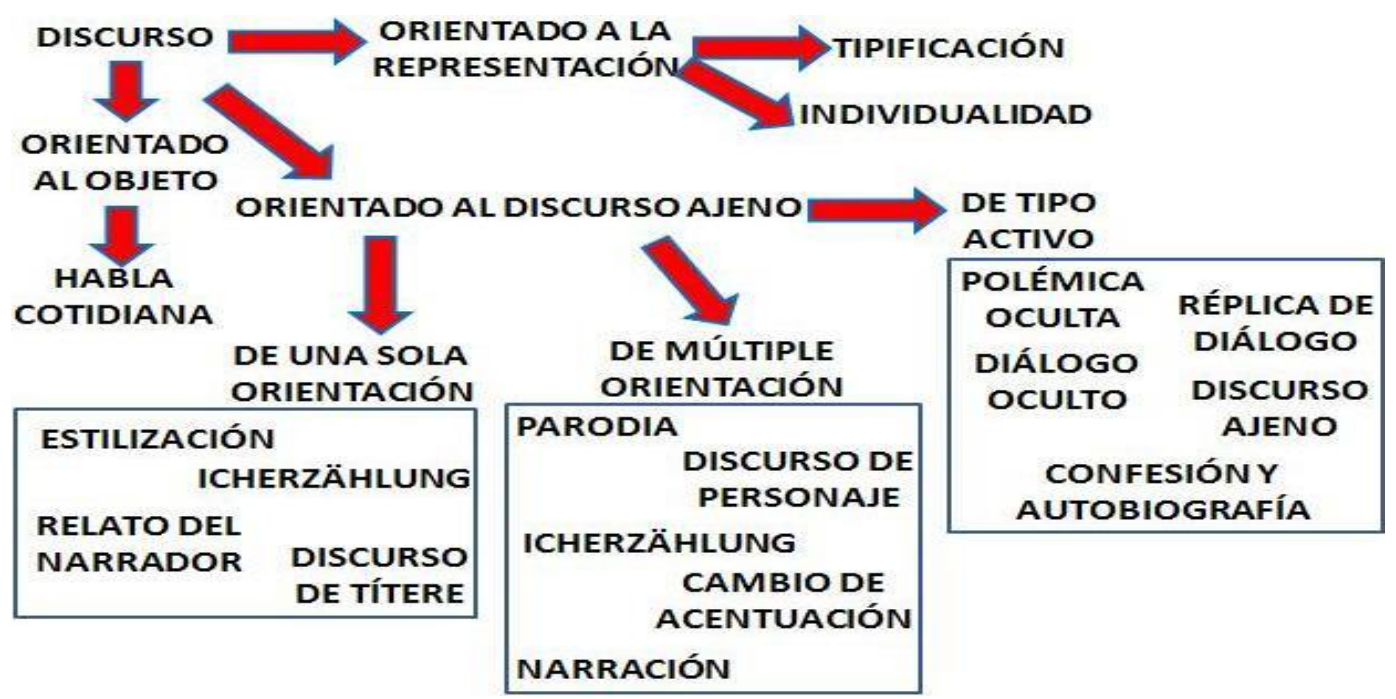

Bajo esta síntesis teórica bajtiniana es que se planteó la implementación de un método identificado como dialógico, el cual trabajó la lectura en profundidad desde la antropología, en la identidad de las personas "pasocanoenses". El punto de partida para cimentar esta investigación en la dialógica, giraba en torno a que el sujeto costarricense y el panameño se distinguían del "otro", pero en la construcción de su "yo" lo adscribían como coprotagonistas de sus vidas, lo cual crea una imagen de convivencia binacional armoniosa, en un espacio fronterizo. La gente en su cotidianeidad unía lo que el límite fronterizo separó: dos países que se consideran hermanos, pero se destrozaron en 1921 en la Guerra de Coto. Como cuenta don Antonio, funcionario de aduana del lado panameño: 
Eso fue por errores de Gobiernos pasados. Gobierno es Gobierno, la gente es aparte. Nosotros somos hermanos y eso es lo que importa (Antonio, comunicación personal en Paso Canoas, 3 de noviembre de 2010).

Este suceso fue la confrontación militar que ambos países tuvieron por reclamar la legítima posesión de la Zona Sur actual de Costa Rica. Este suceso lo ganó Costa Rica gracias a la intervención de Estados Unidos, ya que los empresarios bananeros necesitaban que los cultivos desarrollados en el Sur quedaran en Costa Rica, pues tenían cultivos en la provincia panameña de Chiriquí y eso promulgaba prácticas monopolísticas. No obstante, Panamá lo ganó en el plano militar. Entonces, a pesar de que Costa Rica hiere el orgullo panameño con este conflicto, las personas de la región logran perdonar y forjarse un futuro integrándose estratégicamente, sea con tratados limítrofes, tratados de libre comercio, proyectos conjuntos como el Parque Internacional de La Amistad y demás.

Con esta presentación de elementos de la teoría dialógica, se procede a explicar cómo esta teoría aporta al ejercicio etnográfico, en virtud de la experiencia de investigación desarrollada en Paso Canoas.

\section{Método dialógico: etnografía interdisciplinaria en profundidad}

La construcción metodológica que brinda la teoría dialógica posee múltiples aplicaciones. Para el caso particular de la tesis desarrollada en Paso Canoas, respondió a un ejercicio etnográfico que va más allá de la etnografía convencional. Cuando se habla de una lectura en profundidad, se hace alusión a identificar cómo se relacionan tiempo, espacio y marco de relaciones en la vivencia de los sujetos estudiados (sean los personajes de las obras de Dostoievski o sean las personas que habitan y transitan Paso Canoas), tal como se indicó en el apartado anterior.

La etnografía estudia esas dimensiones efectivamente, pero no lo hace con el estricto sentido de programar metodológicamente ejercicios que las estudien. Una lectura en profundidad demanda que se investiguen estos 
componentes con clara presencia a nivel metodológico. Una etnografía puede indagar percepciones sobre estos temas mediante preguntas en una entrevista, mas no las estudia como tal. Por eso, interdisciplinariamente se articuló el trabajo histórico junto con el geográfico, los cuales se encargaron de desarrollar las vivencias del espacio y tiempo en las relaciones de convivencia humana en Paso Canoas, al partir de lo que la etnografía arrojaba. A nivel de cronograma, la investigación inició con reconocimiento de elementos temporales y espaciales que, según las personas, marcan la dinámica cultural de Paso Canoas, para entonces ser construidos con trabajo de las disciplinas anteriormente citadas.

Se partió de que el método dialógico se recomienda para estudios explicativos, pues la lectura en profundidad permite responder a los porqués de los hechos sociales, plasmados como novelas dialógicas en la vida cotidiana, puesto que:

Los estudios explicativos van más allá de la descripción de conceptos o fenómenos o del establecimiento de relaciones entre conceptos; están dirigidos a responder a las causas de los eventos físicos o sociales. Como su nombre lo indica, su interés se centra en explicar por qué ocurre un fenómeno y en qué condiciones se da éste [...] (Hernández, Fernández y Baptista, 1998, p. 66).

En este sentido, es que nace la práctica de la antropología dialógica, la cual se aboca a estudiar los procesos de diálogo "yo-otro" en la construcción de identidades desde la teoría bajtiniana. Los referentes mayores para Latinoamérica (no todos) se encuentran relacionados con la construcción del "yo indígena" que dialoga con el "otro occidental". Este argumento empezaba a estigmatizar los estudios de antropología dialógica en la relación indiooccidente; sin embargo, con el estudio de Paso Canoas, se replantearon los alcances originales de esta especialidad. 
Aquí el diálogo se da entre un "yo-costarricense" con un "yo-panameño", en el cual coexisten la posibilidad de ser "yo" distinguido del "otro", en donde se adscribe al "otro" como parte del "yo". En el plano del diálogo "yo-indígena" con otro-occidental, es un diálogo de divorcio, cosa que no sucede en el caso de los diálogos transfronterizos. El antropólogo dialógico mexicano José Alejos deja esta idea clara en sus estudios sobre los mayas:

La premura por el rescate etnográfico de los rasgos culturales distintivos de los mayas contemporáneos obedecía a la convicción de ser éstos supervivencias fragmentarias de la asombrosa civilización precolombina, revelada en sus cuantiosos vestigios arqueológicos. Congruente con el pensamiento positivista de la época, esta particular orientación arqueoetnológica condujo a los antropólogos a construir imágenes identitarias de los indígenas en términos de 'rasgos esenciales', 'elementos diacríticos', 'núcleos duros', etcétera, mientras que la gente del entorno, considerada no indígena, fue absolutamente ignorada, o en todo caso, vista sólo como un contraste, como lo "no indio" (Alejos, 2004, p. 2).

En el plano de las nacionalidades, dialogando en una región transfronteriza, existe la noción de tener una identidad distinta a la del vecino, con quien se construye cotidianeidad, pero no remarca la idea de separarse de él. Al contrario, resulta estratégico ser aliado partiendo de la diferencia, para poder construir la noción de comunidad. En el caso maya, los discursos de indio y ladino se remarcan en la separación; en la convivencia transfronteriza, integran.

De este modo, se diseñó la noción interdisciplinaria que desarrollaría el método dialógico para este estudio. La teoría dialógica y la lectura en profundidad es actualmente utilizada por la filología para análisis literario, por lo que esta disciplina brindó los criterios conceptuales y sentó un antecedente de lectura en profundidad actualmente. La historia abarcó la noción de suelo (relacionada con el tiempo). La geografía contempló la idea de medio (asociada con el espacio). La antropología brindó los referentes de la tierra (vinculada con la materialidad y las relaciones interpersonales). 
Esto en sí representó un desafío, en tanto se tuvo conciencia de que un tema de naturaleza compleja, como el de la convivencia transfronteriza, no podía explicarse con una etnografía llevada a cabo bajo los estándares metodológicos que la caracterizan. La etnografía se construye en el presente, pero con las dinámicas actuales era necesario un viaje al pasado que trascendería el potencial de una anécdota. Además, para comprender las lógicas de convivencia binacional en la comunidad, había que entender el modo en que se entendía Paso Canoas como concepto geográfico. La perspectiva que ya se expuso de Bajtin sobre lectura en profundidad, brindaba los elementos pertinentes para superar la brecha metodológica que se presentó para los alcances de la investigación. Por eso, se adoptó lo que la antropología dialógica brinda, al darle aplicabilidad antropológica a una teoría que actualmente se cataloga dentro de las disciplinas lingüísticas y filológicas.

No obstante, al hablar de antropología dialógica, se señala que la disciplina que guiará todo el trabajo es la antropología. La profundidad histórico-geográfica que estas disciplinas brindarían, surgirían de lo que el ejercicio etnográfico fuera delatando desde las voces ocultas; es decir, aquellos elementos del discurso binacional de Paso Canoas que no emergen de la cotidianeidad con que costarricenses y panameños conviven. Cabe señalar que, aunque se apostó por una construcción metodológica interdisciplinaria, se necesitó una disciplina que orientase el actuar de las otras. De ahí que la antropología guiara los distintos procesos.

Las relaciones entre habitantes de Paso Canoas de Costa Rica y Panamá se convertían así en tema de una novela dialógica que se leyó desde la dialógica, explicando por qué esas relaciones, identificadas como binacionales, existen. Fue desde criterios abocados a los sujetos; desde el panameño (identificado como colombiano de 1821 a 1903), el costarricense, el sureño, el chiricano, el migrante, el indígena reducido o exterminado y demás.

En primer lugar, se dio un sentido dialógico a la construcción paradigmática, al establecerlo desde la triada de relaciones de Bajtin. En el abordaje desde el paradigma cualitativo, se reconoció que el primer plano correspondía al del investigador, planteado desde esta reflexión: 
Es importante rescatar la manera en que yo, como investigador, me vi frente a los sujetos. Uno de los motivos por los que me interesa trabajar con personas "pasocanoenses", en una mezcolanza de costarricenses y panameños, es porque yo me siento "como uno de ellos". Cuando trabajé varios años como profesor en la comunidad, se desarrolló en mí un "impulso mecánico" de participar en esa dinámica cotidiana binacional (Muñoz, 2011, p. 62).

Dadas experiencias previas de convivencia en Paso Canoas, donde trabajé como docente en la comunidad durante casi 6 años y se vivía allá en los períodos de vacaciones de diciembre a febrero de cada año, el "yo" estaba imbuido en la dinámica del "otro" y se hacía necesario participar de ella. El investigador no vive de forma permanente en la región, solo los fines de semana por su trabajo de docente, pero se identificaba a sí mismo como local. De este modo, el investigador se construye en el plano del "yo-para-mí" bajo contradicción coexistente, donde al ser ajeno del espacio del "otro", logra adscribirlo a su "yo"; es decir, se identifica "pasocanoense" sin serlo de hecho.

Seguidamente, la percepción que se tenía de las personas "pasocanoenses" es importante, así como el rol protagónico que tienen de la novela dialógica de su vida, para delimitar las estrategias de contacto y de interlocución en el ejercicio etnográfico, así como los límites, por asuntos obvios de respeto. Es así que desde el plano del "otro-para-mí" se notó que:

En ellos existe conciencia de los procesos de convivencia tico-canalera, pero no hay una exploración ni explicación. Su percepción de la cotidianeidad se aboca a una asunción circunstancial: saben cómo viven, pero no vislumbran un porqué. Ellos aprueban la condición armoniosa en que se desenvuelven a nivel binacional en una misma comunidad, pero no conciben elementos de contradicción en ese discurso que predican. No pretendo darles un motivo de su convivencia, sino que, a partir de mis insumos investigativos, ellos mismos puedan mirar introspectivamente y generar sus propias razones de integración. Para ellos, su relación se gesta en una dinámica de horizontalidad, por lo cual debo mantener esa postura frente a ellos. 
Les guardo un profundo respeto como personas, por lo cual debí conservar íntegro lo que ellos deseaban compartir conmigo en el proceso de investigación, y no forzar o cooptar sus aportes en ningún momento. Son facilitadores en el plano investigativo, pero son paisanos en el plano personal, y ambos planos coexistieron en el proceso de este trabajo (Muñoz, 2011, p. 63).

En las primeras experiencias etnográficas, los habitantes de Paso Canoas manifestaban no tener idea (en términos de conciencia) de por qué vivían en armonía con ese pasado lleno de rencores, o bajo qué necesidad se articulaban en una comunidad binacional. Estos temas se fueron profundizando conforme avanzó la investigación, para que las personas generaran conclusiones propias sobre su esquema de cotidianeidad y convivencia.

Finalmente, esta investigación perseguía fines de reivindicación de los habitantes de Paso Canoas de Costa Rica y Panamá, de la antropología dialógica costarricense y, ante todo, una reflexión sobre la integración social por encima de límites fronterizos, tomando la frontera de Paso Canoas como un lugar ejemplar a nivel mundial. Esta comunidad representa la única frontera del mundo entre dos países sin ejército, que ha logrado articular estrategias de integración y crecimiento conjunto, situándolos entre los países de mayor calidad de vida en América Latina. Pero esto debía reflejarse a lo largo de toda la investigación, por lo cual se planteó una postura política en el plano del "yopara-otro", donde:

Finalmente, mi mayor meta fue rescatar Paso Canoas como una frontera singular, que sabe articularse como un espacio de convivencia fronteriza, en el plano de la globalización, y que no se deja intimidar por las políticas de terrorismo, xenofobia y demás. Este trabajo traspasa los límites de Costa Rica y Panamá, y sirve para solucionar eventualmente conflictos internacionales, a partir de una reflexión política de las propuestas que esta investigación generó (Muñoz, 2011, p. 64). 
Ya propiamente en la experiencia de campo, se partió con el trabajo etnográfico, el cual fue el motor y guía de la investigación. Conversando con la gente, tanto costarricense como panameña (y de otras nacionalidades), se encontraron cronotopos, vivencias particulares y demás, complementando estos hallazgos con la tipología discursiva de Bajtin, para detectar diálogos. Como se indicó anteriormente, la novela se construye desde un autor que interpela a un lector sobre un héroe, el cual adquiere autonomía de conciencia en la obra, desde el contexto del autor:

... o sólo la realidad del héroe mismo sino también el mundo exterior que lo rodea y la vida cotidiana se integran al proceso de la autoconciencia, se transfieren del horizonte del autor al del héroe. Ya no se encuentran en el mismo plano que el de éste, junto con él y fuera de él, en el mundo único del autor [...] (Bajtin, 2003, p. 77).

Es así que, desde esta línea, los sujetos "pasocanoenses" se muestran como héroes generados de dos autores: los discursos nacionales de Costa Rica y de Panamá. Y como el héroe en su autonomía reconfigura el mundo del autor, se hacía necesario conocer ese mundo y su paralelo heroico. Conociendo el mundo del autor, es viable profundizar en la conciencia de los sujetos. Para ello, la historia y la geografía trabajaron las relaciones socioeconómicas y políticas entre Costa Rica y Panamá y cómo éstas influyeron en el "otro". Este fue el punto de partida:

Tomando la cotidianeidad de ticos y canaleros, la convertí en una novela dialógica donde yo era un personaje más que "aparecía en escena". En ella vivencié las distintas mecánicas que se gestan en Paso Canoas como población binacional y punto oficial de tránsito entre Costa Rica y Panamá (Muñoz, 2011, p. 65).

Definido esto, se trazaron las categorías sobre la que cada disciplina trabajaría eventualmente, por sospechas iniciales. Estas fueron confirmadas y ampliadas. Esto porque, tras desarrollar el trabajo etnográfico, surgió una inquietud: Paso Canoas no se explicaba por sí misma. La cotidianeidad 
binacional de Paso Canoas remitía a la Zona Sur de Costa Rica y la provincia panameña de Chiriquí. Como espacio novelesco contemplaba desde San Isidro de El General en Costa Rica hasta Tolé en Panamá. A lo largo de la historia, desde tiempos precolombinos, venía tejiéndose una trama compleja de relaciones socioeconómicas y políticas que desembocaron en Paso Canoas como centro, eje y motor de una región transfronteriza más amplia, que alberga muchas comunidades en un trayecto de más de $200 \mathrm{~km}$ sobre la carretera Interamericana: la Gran Región Sur-Chiricana. Con este argumento, las categorías quedaron de esta manera:

Figura 3

Categorías de investigación

\begin{tabular}{|c|c|c|}
\hline & & \\
\hline $\begin{array}{l}\text { xpresiones } \mathrm{Cl} \\
\text { midas, } \text { fes } \\
\text { acionales y } \mathrm{re}\end{array}$ & $\begin{array}{l}\text { Relaciones diplomáticas: } \\
\text { surgimiento de las } \\
\text { provincias de Costa Rica } \\
\text { y Panamá, Ruta de } \\
\text { Mulas, independencia, } \\
\text { Guerra de Coto, tensión } \\
\text { limítrofe, actualidad }\end{array}$ & $\begin{array}{l}\text { Consumo material e } \\
\text { ideología nacional: } \\
\text { productos locales que } \\
\text { remiten a lo nacional, } \\
\text { expresiones del territorio } \\
\text { como nación, fechas } \\
\text { patrias, vínculos con los } \\
\text { símbolos nacionales }\end{array}$ \\
\hline s: & $\begin{array}{l}y \\
\text { refug } \\
\text { bina }\end{array}$ & $\begin{array}{l}\text { tas } \\
\text { hos, } \\
\text { as }\end{array}$ \\
\hline$m_{f i}$ & $\begin{array}{l}\text { Nuev } \\
\text { comp } \\
\text { canto } \\
\text { de de }\end{array}$ & $\begin{array}{l}\text { Trazado del límite: } \\
\text { reconocimiento del } \\
\text { cambio de país al cruzar }\end{array}$ \\
\hline
\end{tabular}

Partiendo de esto, se definieron las técnicas. Desde la disciplina guía, la antropología, se abordaron dos: la observación participante y la conversación. La primera se ejerció de manera clásica, contemplando detalles sobre el espacio, las relaciones de la gente, la circulación de personas en los puestos migratorios, el comercio binacional y demás. Las conversaciones surgieron como un replanteamiento profundo de las entrevistas. En un ambiente de confianza (como se detalló en la construcción paradigmática), la entrevista 
representaba una formalidad capaz de desdibujar la naturalidad con que se trabajaba en el campo. Por lo tanto:

Con personas conocidas, hablaba "de lo que fuera" (según la guía) cuando nos veíamos. Si eran desconocidos (por ejemplo, con las personas que hacían trámites con sus pasaportes), iniciaba con una pregunta o comentario. Por ejemplo: “¿Qué lentos son para atender!”, “¿Esta es la fila para salir de Costa Rica?”, “¿Dónde está el señor que vende los timbres de Chiriquí?" y demás. Con esto, lanzaba al aire algún tema [...] y las personas me hablaban al respecto. Yo les contaba que estaba haciendo mi tesis, y entonces ellas me autorizaban a tomar nota de la conversación. Nunca tuve negativas o quejas al respecto. Al contrario, fue muy fluido y gratificante (Muñoz, 2011, p. 66).

Se tocaron diversos temas, como la identidad costarricense, la identidad panameña, Costa Rica y Panamá como países hermanos, otros migrantes (de Nicaragua, Colombia, Estados Unidos y demás), turismo comercial, la crisis bananera, los desastres naturales que han afectado Paso Canoas (inundaciones y terremotos), la Guerra de Coto y demás. Los temas familiares eran el punto de inicio; los álgidos, el cierre. No obstante, sí hubo entrevistas, con profesionales de la antropología y de las otras disciplinas, así como matrimonios binacionales residentes en Paso Canoas.

En el plano de la historia, la técnica de consulta de fuentes fue la herramienta indicada. Las fuentes -tanto primarias como secundarias- se consultaron en archivos nacionales y eclesiásticos, bibliotecas, universidades y colecciones, de Costa Rica y Panamá. El referente central de búsqueda era todo lo social que los sujetos de Paso Canoas expresaban en las interlocuciones, a través de fuentes documentales.

En la implementación de la geografía, se hizo una reflexión epistemológica sobre el valor de un mapa para los sujetos sociales: 
Trabajé con la técnica del mapeo social: elaborar un mapa en colaboración con los habitantes interpelados. Yo hice el mapa base y ellos le aportaron elementos para definir Paso Canoas desde su propia percepción. Generé empoderamiento territorial, pues se ha dicho que territorio no mapeado, no es reconocido como propio. Métodos como el de etnocartografía y la cartografía participativa apelan a esta práctica (Muñoz, 2011, p. 69).

El trabajo consistió en elaborar un mapa binacional de Paso Canoas. Existían mapas de Paso Canoas de Costa Rica y Panamá, pero ninguno binacional. Para ello, se tomaron los mapas censales de cada país y se recorrió cada calle de la comunidad, en ambos lados, identificando cada casa, local y lote. Se hizo una reconversión de escala del mapa panameño para que coincidiera con el costarricense. El hecho de que ambos mapas de una misma comunidad tuvieran diferente escala indica claramente que los territorios, en tanto sus mapas, han sido apropiados para dividir. Era necesario reivindicar entonces la unión que las personas "pasocanoenses" practican.

Elaborado el mapa, se le trazó el límite fronterizo y se pidió a algunas personas residentes que apelaran al mapa: ¿Qué ven? ¿Qué le falta? ¿Qué le modifican? ¿Qué sienten? Así, el mapa era replanteado con los criterios de las personas, lo cual les generaba empoderamiento al reconocer su territorio como uno, perteneciente a dos países, pero uno en sí mismo. La experiencia propia del mapa se contemplará en un próximo artículo.

También, se planteó la elaboración de mapas que ubicaran trazados limítrofes históricos, la construcción del Sur y Chiriquí como una región binacional, la comprensión de la Guerra de Coto desde una lectura de mapas y demás aportes que brindara la geografía. Aunado a esto, era importante rescatar la vivencia de las experiencias etnográficas con fotografía, la cual se complementó idóneamente con los mapas. Se tomó al menos una fotografía por cada lugar visitado, y en varias oportunidades, los sujetos de interlocución eran quienes sugerían qué fotografiar. 
Con esto, se generó un trabajo de investigación completo, profundo e innovador, que reivindicó la comunidad binacional de Paso Canoas y replanteó los aportes de la antropología dialógica latinoamericana. Costa Rica ha hecho esfuerzos en esta materia, como el estudio del Dr. Marcos Guevara (2004) con los indígenas bribris, referente a las dos maneras de decir el pronombre "nosotros" en su idioma (entre otros temas), como una crítica y reflexión epistemológica de la etnografía:

Los bribris tiene dos vocablos para lo que en español llamamos nosotros: se' (nosotros incluyente) y sa' (nosotros excluyente). La diferencia entre un nosotros incluyente y un nosotros excluyente, permite a los bribris distinguir en la conversación cuando hablan de un nosotros que no involucra a toda la sociedad sino a una pequeña comunidad de personas (Guevara, 2004, p. 216, cursivas del original).

\section{Innovación e interdisciplinariedad: aportes para desarrollar la antropología costarricense}

El motivo principal de este artículo fue presentar el método dialógico, como un esfuerzo interdisciplinario proponente y como una invitación a incentivar en Costa Rica la antropología dialógica, así como los estudios de límites y fronteras, abandonados por la antropología costarricense. Valga este comentario para señalar de manera crítica que, según mi opinión, la antropología costarricense ha entrado en un juego de manías temáticas. Valga que alguien proponga un tema en una investigación y de ella salen hasta 20 estudiantes desarrollando lo mismo, agotándolo, reduciendo la variabilidad de las investigaciones y abandonando otros temas de igual o mayor relevancia. Se pretende invitar al futuro cuerpo profesional de la antropología costarricense a explorar el método dialógico, pero, por favor, que no se convierta en una manía.

Sin temor a la equivocación, la antropología costarricense ha mostrado un desarrollo sobresaliente desde sus inicios. En Latinoamérica, los nombres de doña María Eugenia Bozzoli y don Carlos Aguilar Piedra han resonado y 
siguen vigentes. De estos grandes visionarios han crecido nuevas figuras en el quehacer académico de la disciplina en el país, quienes en su función docente, de acción social y de investigación están creando una nueva generación, sensible a la realidad nacional y a los sectores desprotegidos ante los embates de la globalización.

Un reto para la nueva generación es fomentar la interdisciplinariedad, como ejercicio de crecimiento académico. No de crecer sin sentido alguno, sino en aras de producir conocimiento más profundo, de mayor alcance en sus resultados y planteamientos. Desde la experiencia en Paso Canoas, se demuestra que la integración de la historia, la filología y la geografía generó una investigación que, de haberse abordado sólo etnográficamente, no hubiera tenido el mismo impacto. No es en detrimento de la etnografía, pero el mundo precisa respuestas más profundas a problemas más complejos. Y como dicta el adagio que "dos cabezas piensan mejor que una", es válido pensar que "dos disciplinas piensan mejor que una".

La experiencia del método dialógico requirió aprendizaje extracurricular a la formación antropológica. Demandó un curso de dialógica en el posgrado de Literatura, un curso especializado en análisis espacial, capacitaciones sobre sistemas informáticos para bases de datos (puesto que la investigación trabajó con más de 300 fuentes escritas y 80 conversaciones), aprendizaje en cartografía, metodología histórica y manejo archivístico de documentos antiguos. Todo este conocimiento adquirido representa una ganancia en cuanto a crecimiento profesional y académico, que invita a conocer más de otras disciplinas para proyectos futuros e innovar. Las grandes teorías que han marcado la historia del conocimiento, nacieron de innovaciones, nuevas percepciones, proposiciones a veces consideradas atrevidas o incoherentes, pero terminaron dictando cátedra. Por lo tanto, para la nueva generación de profesionales en Antropología que se viene gestando en Costa Rica, les queda un gran reto: innovar, por la academia, por la gente, por el país, por Latinoamérica. La interdisciplinariedad les da un gran apoyo para esto. 
Finalmente, este texto queda como un manual de consulta sobre la teoría dialógica. A su vez, guarda una manera de implementar antropológicamente esta teoría, mas no como un recetario de seguimiento estricto, sino como una puerta de invitación a que se innove metodológicamente, para enriquecer la disciplina antropológica y generar futuros proyectos de investigación, asociados con nuevas temáticas o con aportes y discusión. La invitación queda hecha.

\section{Referencias bibliográficas}

Alejos, J. (1998). "Mayas, ladinos y occidente: antropología e identidad en perspectiva dialógica". Acta poética.18-19 (1), 303-317.

Alejos, J. (2006). "Identidad y alteridad en Bajtin". Acta poética, 47(1), 47-61.

Bajtin, M. (2003). Problemas de la poética de Dostoievski. México D.F.: Fondo de Cultura Económica.

Bubnova, T. (1996). Bajtin en la encrucijada dialógica (datos y comentarios para contribuir a la confusión general). En I. Zavala (Coord.), Bajtin y sus apócrifos. San Juan, Puerto Rico: EUPR.

Cros, E. (1997). El sujeto cultural. Sociocrítica y psicoanálisis. Buenos Aires: Ediciones Corregidor.

Guevara, M. (2004). "Por una epistemología nuestra. Política y antropología desde los Bribris". Anales de Antropología, 38, 201-228.

Haba, P. (1994). "Metodologías, métodos, metodologismo. Prolegómenos a una crítica de la autocomprensión 'misionera' en los científicos sociales”. Revista de Ciencias Sociales, 64, 109-119. 
Hernández, R. C. Fernández y Baptista, P. (1998). Metodología de la investigación. México DF: McGraw Hill.

Medvedev, P. y Bajtin M. (1994). El método formal en los estudios literarios. Introducción crítica a una poética sociológica. Madrid: Alianza.

Muñoz, J. (2011). Construyendo identidades en armonía con los vecinos. Un estudio antropológico de la comunidad binacional de Paso Canoas, frontera Costa Rica-Panamá. Una aproximación dialógica. Tesis de maestría no publicada, Universidad de Costa Rica, San José, Costa Rica.

Rodríguez, F. (2004). Autobiografía y dialogismo: el género literario y El río: novelas de caballería. San José: Editorial de la Universidad de Costa Rica.

Voloshinov, V. (1995). El discurso en la realidad y el discurso en la poesía: en torno a las cuestiones de la poética sociológica. En E. Volek (Comp.), Antología del formalismo ruso y el grupo de Bajtin. Semiótica del discurso y posformalismobajtiniano, Volumen II (pp. 197-227). Madrid, España: Fundamentos.

Voloshinov, V. y Bajtin, M. (1992). El marxismo y la filosofía del lenguaje. Madrid: Alianza. 